\title{
«LA INFANTA SE HA DE CASAR CON QUIEN FACILITE LA PAZ O DISPONGA LOS MEDIOS PARA LA GUERRA»1. LAS NEGOCIACIONES PARA LA REALIZACIÓN DEL MATRIMONIO ENTRE LA INFANTA MARÍA TERESA Y LEOPOLDO I (1654-1657)
}

\author{
Rocío MARTínez LóPEZ ${ }^{2}$ \\ Universidad Nacional de Educación a Distancia (UNED)
}

Fecha de recepción: enero 2015

Fecha de aceptación: marzo 2015

\section{ESTADO DE LA CUESTIÓN: EL PROYECTO SUBESTIMADO}

El problema de la sucesión de la Monarquía Hispánica ha sido un tema que ha despertado la atención de incontables historiadores a lo largo de las centurias. Sin embargo, no se ha dedicado la misma atención al estudio de las dos hermanas supervivientes del último rey de la dinastía Habsburgo en España, las infantas María Teresa y Margarita, y a la importancia dinástica y política que ambas tuvieron en relación a este conflicto, pese a que sus matrimonios están intrínsecamente unidos a la problemática sucesoria, aunque es bien cierto que en los últimos años han surgido publicaciones de gran calidad que han mejorado nuestro conocimiento de la vida de ambas infantas.

1. Carta de Felipe IV al Marqués de La Fuente, su embajador en Viena, fechada el 22 de marzo de 1656. Archivo Histórico Nacional, Estado, libro 133, s/f.

2. Este artículo presenta parte de la investigación llevada a cabo en mi memoria de Fin de Máster, que se presentó en la universidad Autónoma de Madrid como parte del Máster en Estudios Avanzados en Historia Moderna «Monarquía de España (siglos XVI-XVIII)», dirigida por el profesor Antonio Álvarez OsorioAlvariño. Dicha investigación ha sido ampliada y mejorada durante mis estudios de doctorado, realizados en la Universidad Nacional de Educación a Distancia (UNED) bajo la dirección del profesor Luis Antonio Ribot García y vinculados al proyecto de investigación titulado «Conservación de la Monarquía y equilibrio Europeo entre los siglos XVII y XVIII» (HAR2012-37560-C02-01). Mi más sincero agradecimiento tanto para Luis Antonio Ribot García como para Antonio Álvarez-Osssorio por su paciencia, comprensión y ayuda. 
Son especialmente relevantes en este sentido los recientes trabajos de la doctora Laura Oliván Santaliestra, como los dedicados a la niñez de ambas infantas ${ }^{3}$, a la vida de la ya emperatriz Margarita en Viena ${ }^{4}$ y al gobierno de la reina Mariana de Austria ${ }^{5}$. Pero, pese a estos avances y los de otros autores, es mucho todavía lo que queda por descubrir de la vida de estas infantas, que concentraron durante décadas la atención de media Europa por su condición de posibles herederas de Felipe IV y Carlos II.

Pasando en concreto a examinar el caso de la infanta María Teresa, es interesante destacar la poca atención que ha suscitado una circunstancia como la que ahora vamos a analizar, que condicionó enormemente las relaciones entre la Monarquía Hispánica y el Sacro Imperio durante años: el proyecto para casar a la infanta María Teresa con los herederos de Fernando III, primero con Fernando IV y, tras su muerte, con el que llegaría a ser Leopoldo I, que se convirtió en un elemento dominante en los intercambios diplomáticos llevados a cabo entre las cortes de Madrid y Viena en los años posteriores a la paz de Westphalia.

En líneas generales, este matrimonio no ha pasado de ser una simple anécdota en la mayoría de los libros dedicados a la problemática sucesoria, al estudio de las relaciones entre los Habsburgo de Viena y Madrid, a los últimos años de Felipe IV o en las biografías de algunos de los protagonistas de este proyecto matrimonial. Así, por ejemplo, en la obra de referencia que escribieron Ferdinand Opll y Karl Rudolf dedicada a las relaciones entre España y Austria, estas negociaciones tan relevantes en su momento apenas reciben una breve mención ${ }^{6}$, mientras que en algunas de las obras biográficas dedicadas a Leopoldo I más destacadas, como la escrita por John P. Spielman o la realizada por Jean Bérenger, apenas lo mencionan como un proyecto que nunca llegó a ser más que un mero deseo ante el interés manifiesto que presentaba la poderosa Francia por conseguir la mano de la infanta para el joven Luis XIV $\mathrm{X}^{7}$. Asimismo, este último enlace ha dominado la atención la mayoría de los historiadores, hasta el punto

3. Olivín Santaliestra, Laura: «My sister is growing up very healthy and beautiful, she loves me». The childhood of the Infantas Maria Teresa and Margarita Maria at court», en Coolidge, Grace E.: The Formation of the Child in Early Modern Spain, Dorchester, 2014, pp. 165-188.

4. Oliván Santaliestra, Laura: «Giovane d'anni ma vecchia di giudizio». La emperatriz Margarita en la corte de Viena», en Martínez Millán, José, y González Cuerva, Rubén (coords.): La dinastía de los Austria. Las relaciones entre la Monarquía Católica y el Imperio, Madrid, 2011, vol. 2, pp. 837-908.

5. Olivín SAntaliestra, Laura: Mariana de Austria: imagen, poder y diplomacia de una reina cortesana, Madrid, 2006.

6. Opll, Ferdinand, y Rudolf, Karl: España y Austria, Madrid, 1997, pp. 139-140.

7. Spielman, John P.: Leopold I of Austria, Londres, 1977, pp. 45 y 52-54 y Bérenger, Jean: Léopold Ier (1640-1705). Fondateur de la puissance autrichienne, París, 2004, p. 242. De hecho, Spielman indica que en Madrid y en Viena se asumía que María Teresa se acabaría casando con el heredero de Fernando III, pero que la exigencia de Mazarino de que la infanta se casase con Luis XIV para sellar la paz acabó con cualquier proyecto matrimonial de esta índole que pudiera haberse negociado. Por su parte, Bérenger utiliza el interesante calificativo de «s'imagina» cuando comenta que Leopoldo pensaba que iba a casarse con la infanta María Teresa, como si las negociaciones matrimoniales a este respecto apenas hubieran sido más que un vago deseo, antes de indicar que las negociaciones para firmar la paz iniciadas en 1658 acabaron para siempre con tal deseo del joven emperador. 
de que este proyecto previo, de enorme importancia, como a continuación se verá, ha pasado a estar prácticamente ignorado como una simple posibilidad que no llegó nunca a traducirse en ninguna negociación concreta.

De hecho, ha sido precisamente la historiografía alemana la que ha vuelto a centrar la atención en este proyecto matrimonial fallido que pudo llegar a cambiar de forma decisiva el devenir de los acontecimientos. En un intento muy exitoso de revisar la figura del emperador Fernando III, estudiando su gobierno más allá de la guerra de los Treinta Años con la que tradicionalmente se le ha asociado, autores como Mark Hengerer $^{8}$ y, sobre todo, Lothar Höbelt, han arrojado mucha luz en lo referente a las espinosas relaciones diplomáticas que se establecieron entre el Imperio y la Monarquía Hispánica después de la firma de la paz de Westphalia, entre las que las negociaciones del enlace entre María Teresa y Leopoldo I tuvieron un lugar especial por los conflictos que despertaron entre ambas ramas de la dinastía Habsburgo. Höbelt, en su libro dedicado a Fernando III titulado Ferdinand III (1608-1657). Friedenskaiser wider Willen ${ }^{9}$, publicado en el año 2008, y especialmente en su artículo titulado «Madrid vaut bien une guerre?» Marriage negotiations between the Habsburg courts, 1653-1657» ${ }^{10}$, hace avances muy importantes en relación al tema que aquí nos ocupa y han sido estos dos trabajos de este destacado investigador los antecedentes directos del artículo que a continuación se presenta. En las siguientes líneas, pretendo presentar una aportación al conocimiento de este proyecto matrimonial que tanta importancia tuvo en la década de los 50 del siglo XVII, desde la perspectiva del gobierno de la Monarquía Hispánica, y analizar cuál fue el comportamiento de Felipe IV respecto a este enlace, desde sus reticencias iniciales hasta que el nacimiento del príncipe Felipe Próspero, a finales de 1657 , abrió la posibilidad de un matrimonio francés para la infanta, acabando con un posible matrimonio que podría haber cambiado de forma radical los destinos de la Monarquía Hispánica, del Imperio y, por tanto, de Europa, si se hubiera producido.

\section{EL INICIO DE LA «GUERRA DIPLOMÁTICA DE SUCESIÓN»: LA MUERTE DEL PRÍNCIPE BALTASAR CARLOS}

«La Monarquía Católica, a falta de real sucesión varonil, se halla en trance de pasar al dominio de príncipes no naturales o extraños. Es lance en que va todo el caudal de España, cuando está la Monarquía tan a pique de pasarse o a príncipes austria$\cos$ (que, en la desdicha, fuera felicidad), o a franceses, totalmente extraños» ${ }^{11}$. Estas

8. Hengerer, Mark: Kaiser Ferdinand III (1608-1657): Eine Biographie, Viena, 2012.

9. HöвELt, Lothar: Ferdinand III (1608-1657). Friedenskaiser wider Willen, Viena, 2008.

10. HöвELT, Lothar: «Madrid vaut bien une guerre?» Marriage negotiations between the Habsburg courts, 1653-1657», en Martínez Millán, José, y González Cuerva, Rubén (coords.): La dinastía de los Austria..., op. cit., vol. 3, pp. 1421-1436.

11. Real Academia de la Historia, colección Salazar y Castro, K-9, fols. 53v. y 60. Citado por VALLADARES, Rafael: La rebelión de Portugal. Guerra, conflicto y poderes en la Monarquía Hispánica (1640-1680), Valladolid, 1998, p. 164. 
palabras, dirigidas por don Luis de Haro a Felipe IV en diciembre de 1646, reflejan claramente los temores de una Monarquía que acababa de ver cómo el único hijo varón del rey, el príncipe Baltasar Carlos, había fallecido repentinamente dos meses antes en Zaragoza. En aquel momento, la infanta María Teresa, nacida el 20 de septiembre de 1638, era la única heredera de la Monarquía Hispánica.

La inestabilidad sucesoria de la Monarquía Hispánica iniciaba así un proceso que desencadenaría, más de cincuenta años después de esta muerte, el estallido de la guerra de Sucesión (1701-1713). El conflicto bélico en sí mismo se puede considerar como el acto final de un enfrentamiento por la sucesión que llevaba décadas produciéndose en el ámbito diplomático. Los problemas sucesorios de la corona española influyeron de forma destacada en la diplomacia europea durante el medio siglo anterior al estallido de la guerra de Sucesión española propiamente dicha, condicionando no solo las relaciones internacionales de las principales potencias implicadas en el problema sucesorio (Francia, el Imperio, Baviera y la propia Monarquía Hispánica), sino también, a menor escala, las de otros territorios europeos, como Inglaterra, Holanda o Saboya. Tratados, paces y negociaciones estuvieron influidas directa o indirectamente por la problemática sucesoria de la rama española de los Habsburgo en el periodo comprendido entre 1646 y 1700, hasta el punto de que podemos hablar de una auténtica guerra diplomática de sucesión en la que los pretendientes a ocupar el trono de la Monarquía Hispánica utilizaron todos los recursos diplomáticos a su alcance para ponerse al frente de la carrera por la sucesión hispana.

Esto no significa que podamos considerar que esta lucha diplomática tuvo la misma importancia en la política europea durante todo el periodo que hemos señalado aquí. En su lugar, podemos apreciar como existen una suerte de fluctuaciones dentro de este enfrentamiento diplomático que indican una mayor o menor importancia internacional de la crisis sucesoria hispana según los acontecimientos que se estuvieran produciendo en los diferentes momentos. Así, se pueden detectar periodos de gran peso del problema sucesorio en la política europea, como los años inmediatamente posteriores a la muerte de Baltasar Carlos, y otros en los que éste, sin desaparecer nunca completamente del ámbito diplomático, tuvo menor relevancia, como el periodo comprendido entre 1657 y 1661, cuando el nacimiento sucesivo de varios infantes pareció asegurar la sucesión masculina de Felipe IV. Por lo tanto, dada la importancia y la extensión que tuvo este fenómeno a lo largo del tiempo, este merece otra denominación que la de simple prolegómeno al estallido de la guerra de Sucesión española. A falta de un mejor término para calificar este periodo, podemos denominarlo como «guerra diplomática de Sucesión», entendiendo por tal el periodo que se desarrolla entre el 9 de octubre de 1646 (fecha de la muerte del príncipe Baltasar Carlos) y el 1 de noviembre de 1700 (día del fallecimiento de Carlos II sin descendencia). En las siguientes líneas, nos vamos a centrar en el estudio de uno de los periodos más destacados de esta guerra diplomática de Sucesión: las negociaciones matrimoniales mantenidas entre el rey Felipe IV y los emperadores Fernando III y Leopoldo I para acordar el matrimonio de la infanta María Teresa con el heredero de los Habsburgo imperiales. 
Las voces de alarma sobre la inestable sucesión de Felipe IV habían empezado a surgir varios años antes de la prematura muerte del heredero, aunque no se consideró un problema político de primer orden hasta los primeros años de la década de los 40 del siglo XVII ${ }^{12}$. Antes de la muerte de Baltasar Carlos, la fragilidad de la descendencia que había tenido Felipe IV de su matrimonio con Isabel de Borbón había inspirado algunos recelos en torno al futuro de la dinastía ${ }^{13}$. Sin embargo, las repetidas instancias hechas a Felipe IV con el objetivo de que este contrajera un segundo matrimonio no recibieron una acogida favorable por parte del monarca ${ }^{14}$, que prefirió comenzar a negociar el matrimonio de su hijo de quince años para conjurar la inestabilidad sucesoria (y, por tanto, política), que se podía derivar de tener un único heredero varón al trono.

Entre las distintas candidatas que se barajaron destacan Isabel Clara de Habsburgo, hija de Leopoldo V del Tirol y Claudia de Médicis; Ana María Luisa de Orleáns, sobrina de Luis XIII como hija de Gastón de Orleans y María de Borbón; Leonor Gonzaga, hija de Carlos y María Gonzaga, y la archiduquesa Mariana, hija de Fernando III y María Ana de Austria, que a la postre sería la elegida ${ }^{15}$. Existieron múltiples razones

12. Aunque Jean Berenguer llega a defender que el matrimonio entre Ana de Austria y Luis XIII, que se acuerda en 1612 y se celebra en 1615, tenía como objetivo vincular la herencia de la Monarquía Hispánica a la corona francesa, esta es una tesis que difícilmente se puede sostener. En el momento en el que se acordó ese matrimonio, Felipe III tenía tres hijos varones (Felipe, Carlos y Fernando) que hacían que las posibilidades de que Ana llegase a convertirse en heredera de su padre fueran muy remotas. No se puede atestiguar que se despertara una auténtica alarma sucesoria en la Monarquía Hispánica hasta 1641, pues en los años anteriores Felipe IV había tenido siempre al menos dos herederos varones a los que podría haber recurrido la Monarquía si se hubiera producido su fallecimiento. Entre 1621, año en el que ascendió al trono, y 1629, tuvo dos herederos en las figuras de sus hermanos Carlos y Fernando y, con el nacimiento de Baltasar Carlos en 1629, la cifra llegó a ascender a tres. A la muerte del infante don Carlos en el año 1632, siguió teniendo dos posibles sucesores en las personas de su hijo y el cardenalinfante Fernando. Asimismo, durante estos años, los embarazos de la reina Isabel de Borbón todavía eran constantes y se podía esperar que Felipe IV pudiera tener más hijos varones. Sin embargo, la muerte del cardenal-infante Fernando en 1641 y el hecho de que la reina Isabel de Borbón no hubiera tenido ningún otro embarazo desde el nacimiento de la infanta María Teresa en 1638 comenzó a despertar ciertas alarmas respecto a la sucesión de Felipe IV, aunque esta no se convertirá en una cuestión de verdadera gravedad hasta la muerte del príncipe Baltasar Carlos en 1646. Bérenger, Jean: «La question de la succession d'Espagne au XVII siècle», en BéLY, Lucien (dir.): La présence des Bourbons en Europe, XVI-XVIII siècle, París, 2003, pp. 75-77.

13. «Los enemigos sacarían esta materia para pasar a designios y los franceses es cierto que no olvidarán el derecho del Rey Cristianísimo sin hacer ningún caso a la renuncia de la reina su madre, excluyendo por derecho y por fuerza el de la Casa de Austria, cuyos príncipes, aunque naturales, no puede negarse que les falta la práctica de estos reinos y sus habitantes». Archivo General de Simancas, Estado, leg. 2.347, Junta de Estado del 8 de enero de 1646. Citado por VAlladares, Rafael: La rebelión de Portugal. Guerra, conflicto..., op. cit., págs 96-97.

14. En una carta enviada a su hermana, la emperatriz María Ana, Felipe IV indica claramente su deseo de no volver a contraer matrimonio. Carta fechada el 21 de abril de 1645. Citada por MaURA Gamazo, Gabriel: Carlos II y su corte, Madrid, 1911, vol. 1, p. 66.

15. Se puede ver un resumen de los puntos a favor y en contra que tenían todas las candidatas aquí indicadas en el documento titulado Papeles politicos tocantes al reinado de Felipe $I V$, Biblioteca Nacional de España, Mss./2080, especialmente en los folios 83v.-87v. 
para esta elección. Entre las principales se encontraba el fallecimiento de la emperatriz María Ana, que se produjo el 13 de mayo de 1646, lo que debilitaba significativamente la influencia española en Viena y, especialmente, la necesidad de estrechar una vez más los lazos entre ambas ramas de la familia ante las crecientes posibilidades de que el Emperador intentara firmar una paz separada con Francia y Suecia, lo que dejaría a la Monarquía Hispánica prácticamente sin aliados en su lucha contra el poderoso reino vecino ${ }^{16}$. Asimismo, durante la revisión de los pros y los contras que tenía este matrimonio, también surgió el fantasma del problema sucesorio, indicándose que era vital contar con la ayuda del Emperador si llegaba el caso de que la infanta Ana quisiese reclamar algún territorio de la Monarquía Hispánica frente al mejor derecho que su renuncia había otorgado a los descendientes de su hermana María, si los dos hijos de Felipe IV sufrían algún «accidente» ${ }^{17}$. En julio de 1646 ya estaba acordado el matrimonio $^{18}$ y se procedió a negociar la jornada de la nueva novia con la mayor celeridad posible.

Sin embargo, las negociaciones de este matrimonio no fueron las únicas que se llevaron a cabo en estos momentos, pues desde la corte imperial se intentó acordar también el matrimonio del futuro Fernando IV de Hungría y la infanta María Teresa. Pero, dada la juventud de la infanta y la posibilidad de que los intereses y necesidades de la Monarquía Hispánica pudieran haber cambiado en el momento en el que se pudiera hacer efectivo cualquier matrimonio de la infanta, esta posibilidad nunca llegó a con-

16. Para ilustrar este punto, podemos ver, por ejemplo, cómo en 1646 el conde Maximilian von Trauttmansdorff, enviado del emperador Fernando III a Münster y uno de los hombres más influyentes del gobierno imperial, había estado a punto de conseguir llegar a un acuerdo de paz entre el Imperio, Francia y Suecia, representando los intereses de una importante facción política de Viena que defendía que lo mejor para el Imperio era firmar la paz y desvincularse de los intereses de la Monarquía Hispánica, algo que causó una gran alarma en la corte de Madrid. HöBelt, Lothar, «Madrid vaut bien une guerre? Marriage negotiations between the Habsburg courts, 1653-1657», en MarTínez Millán, José, y GonzÁlez Cuerva, Rubén (coords.): La dinastía de los Austria ..., op. cit., vol. 3, pp. 1422-1424.

17. «[...] Para la conservación de los Estados de Flandes e Ytalia, estos motivos y la limitada sucesión de estos Reynos y los riesgos grandes que resultan no tan solamente a ellos sino a la Xpristiandad si llegasse casso (lo que Dios no permita) de controvertirse si la renunçiaçion que hiço la Señora Reyna es inbalida o si el derecho que en Virtud de ella tiene la Emperatriz es constante me hicieran anteponer el casamiento del Príncipe Nuestro Señor y de la señora Infante con los que tiene el Emperador a todos los demás, juzgando que no solo se deve en este caso atender a tomar Vuestra Magestad más amigos sino a dejar abierto ningún portillo por donde nuestros contrarios puedan, disminuyendo el número de nuestros aliados, o a lo menos, obrar que estén indiferentes, o que dividan sus intereses de los de esta Corona aquellos Príncipes que por naturaleza, por vínculos y por amistad, se an mostrado siempre afetos y corrido la misma fortuna que las Armas de Vuestra Magestad, [...] y así considerando quan inseparables son los intereses de Vuestra Magestad con los de la Augustísima Casa de Austria desearía nos aprovechásemos de los subjetos que ay en ella, no para repetir parentescos, que con apretados vínculos se hallan ligados, sino para interesar con ellos otros príncipes a la devoción de Vuestra Magestad». Papeles políticos tocantes al reinado de Felipe $I V$, BNE, Mss./2080, fol. 82r.-83v.

18. Así lo indica el propio Baltasar Carlos en una carta enviada a sor Ana Dorotea de Austria al Monasterio de las Descalzas Reales, fechada el 17 de julio de 1646. Archivo General de Palacio, Patronatos de la Corona, Descalzas Reales, Original, Caja 6, exp. 31, fol. 36. 
cretarse antes de que la inesperada muerte de Baltasar Carlos cambiara radicalmente los planes de futuro de Felipe IV $^{19}$.

El 9 de octubre de 1646, la muerte del príncipe dejaba a la Monarquía en una situación más que delicada, pendiente de cualquier accidente que pudiera poner en peligro la salud de Felipe IV. Si el monarca muriese de forma repentina, no solo sería su heredera directa una mujer, con cuyo matrimonio podría introducirse una dinastía extranjera en el gobierno de la Monarquía Hispánica, sino que también hubiera heredado las distintas coronas una menor de edad, sin que hubiera ningún otro miembro de la dinastía en la Península que pudiera ejercer la regencia, en un momento especialmente incierto para una Corona inmersa en la guerra de los Treinta Años y acosada por doquier por problemas de toda índole. De esta forma, la incertidumbre sucesoria se convertía en el principal problema de la Monarquía, como una sombra que planearía sobre ella durante los siguientes cincuenta años del siglo XVII ${ }^{20}$.

\section{«NO SABEMOS SI SERÁ SOLO UNA BUENA INFANTA O ALGO MÁS» ${ }^{21}$ : LA NEGOCIACIÓN DEL MATRIMONIO ENTRE MARÍA TERESA Y EL ARCHIDUQUE LEOPOLDO IGNACIO HASTA LA MUERTE DEL EMPERADOR FERNANDO III}

Inmediatamente después de la muerte de su hijo, Felipe IV se aprestó a intentar conseguir que el estatus de su hija como nueva heredera fuera lo más temporal posible, contrayendo un segundo matrimonio que pudiera darle un hijo varón. La muerte del príncipe había dejado viuda antes incluso de conocer a su joven marido a la archi-

19. Respecto al matrimonio imperial de María Teresa, Luis Tercero Casado defiende que el duque de Terranova, que había sido enviado por Felipe IV a Viena para negociar el matrimonio de Baltasar Carlos con la archiduquesa Mariana, llevaba órdenes de acordar un doble enlace entre sus hijos y los del emperador. Sin embargo, este matrimonio nunca llegó a estar del todo sellado antes de la muerte de Baltasar Carlos y también se había considerado un posible matrimonio entre María Teresa y Luis XIV como forma de sellar la paz en las diversas negociaciones llevadas a cabo entre ambos reinos hasta 1646, sin éxito. Por ejemplo, se habla de que Mazarino había planteado a Felipe IV la opción de una paz separada mediante el matrimonio del joven Luis con María Teresa, quien llevaría como dote los Países Bajos a cambio de que Francia le restituyese Cataluña. Tercero CASADO, Luis: «La jornada de la reina Mariana de Austria a España: divergencias políticas y tensión protocolar en el seno de la casa de Austria (16481649)», Hispania. Revista española de Historia, vol. LXXI, n. ${ }^{\circ} 239$ (2011), p. 643; Solano Camón, Enrique, «Una nueva aproximación en torno a las relaciones políticas entre la corte madrileña y Viena en el último cuarto del siglo XVII», en Martínez Millán, José y, GonZÁlez Cuerva, Rubén (coords.): La dinastía de los Austria ..., op. cit., vol. 2, pp. 1055-1056, y OLIVÁN, Laura: «El fin de los Habsburgo: crisis dinástica y conflicto sucesorio en la Monarquía Hispánica (1615-1700)», en NiETo SoriA, Manuel y López Cordón-Cortezo, María Victoria (coords.): Gobernar en tiempos de crisis: las quiebras dinásticas en el ámbito hispánico: 1250-1808, Madrid, 2008, p. 46.

20. Véase Ribot García, Luis Antonio: «La repercusión en España del tratado de reparto de la Monarquía de 1668», en Sanz Camañes, Porfirio (ed.), Tiempo de Cambios. Guerra, diplomacia y política internacional de la Monarquía Hispánica (1648-1700), Madrid, 2012, pp. 55-96.

21. Carta de Felipe IV a la condesa de Paredes del 22 de diciembre de 1654. Pérez Villanueva, Joaquín: Felipe IV, escritor de cartas. Un epistolario inédito con Velázquez al fondo, Salamanca, 1986, p. 242. 
duquesa Mariana y el emperador, deseoso de no perder la nueva alianza que se iba a forjar, ofreció rápidamente a sus dos hijos mayores al gobierno de Madrid, como cónyuges de Felipe IV y María Teresa respectivamente ${ }^{22}$.

Existieron otras candidatas a la mano del rey, recabando especial atención las archiduquesas Isabel Clara y María Leopoldina del Tirol, pero la opción de Mariana fue rápidamente aceptada, tanto por las mismas razones que habían impulsado al monarca a convertirla en su nuera como por el hecho de que, al estar tan avanzadas las negociaciones, se podía confiar en que el matrimonio se podría celebrar lo más pronto posible ${ }^{23}$. Ciertamente, el matrimonio fue acordado con inusitada rapidez y el 9 de enero de 1647, apenas tres meses después del fallecimiento de Baltasar Carlos, ya se encontraba fijado ${ }^{24}$, aunque la joven novia no saldría de Viena rumbo a Madrid hasta el 18 de noviembre de 1648 .

Acordado este enlace, el deseo de la corte de Viena para concertar el matrimonio entre el archiduque Fernando y la infanta María Teresa se multiplicó. La presión por parte del emperador para asegurar, con este enlace, que la herencia hispana permaneciese en su dinastía solo se había encontrado con excusas y buenas palabras por parte de Felipe IV cuando la firma de la paz de Westfalia el 24 de octubre de 1648 detuvo en seco cualquier negociación diplomática al respecto, pese a las excusas presentadas por el emperador a su primo ${ }^{25}$. Felipe IV consideró públicamente la firma de este tratado

22. Ramírez de Villa-UrRutia, Wenceslao: Relaciones entre España y Austria durante el reinado de la Emperatriz doña Margarita, infanta de España y esposa del emperador Leopoldo I, Madrid, 1905, pp. 56-57. Ese ofrecimiento también lo recoge Jerónimo de Mascareñas, en su obra Viage de la Serenissima Reyna María Ana de Austria, Segunda Muger de Don Phelipe Quarto, deste nombre Rey Cathólico de Hespaña, hasta la Real Corte de Madrid, desde la Imperial de Viena, Madrid, 1650, pp. 8-9.

23. La opción de las archiduquesas tirolesas tuvo una cierta importancia, al ser defendida por aquellos sectores que se oponían al matrimonio imperial. Entre los argumentos que se utilizaron en contra de la elección de Mariana, se encontraban principalmente el hecho de que era aún demasiado joven como para dar a la Monarquía el heredero que tanto necesitaba en poco tiempo, las informaciones que llegaban sobre su frágil salud, que podía afectar a la posible descendencia del matrimonio y los crecientes rumores que acusaban a Fernando III de estar planeando la firma de una paz separada con Francia y Suecia. De hecho, la madre de las archiduquesas, Claudia de Francia, llegó a enviar a un hombre de su confianza a Madrid, el jesuita Eustaquio Pagano, para fomentar esta alianza matrimonial y colaborar con aquellos sectores opuestos a renovar los lazos con el Imperio, aunque no llegó a tener demasiado éxito. Véase Cotejo Phisico-Político de las cosas de Viena y de Inspruck para el mayor acierto en la elección de esposa de que oy necesita la Magestad Cathólica, BNE, Mss./2080, pp. 136v.-154r., documento fechado el 6 de diciembre de 1646. Luis Tercero Casado en su gran artículo sobre la jornada de la reina Mariana, apunta también que Fernando III indicó a su embajador en Madrid, el marqués de Grana, que informase a Felipe IV de la frágil salud de su hija, por el peligro que esto podía suponer para su descendencia. Tercero CASADO, Luis, «La jornada de la reina Mariana de Austria...», art. cit., p. 642.

24. Así se lo indica Felipe IV a sor María de Ágreda en una carta fechada el 9 de enero de 1647. Silvela, Francisco: Cartas de sor María de Ágreda y del rey Felipe IV, Madrid, 1885-1886, vol. 1, p. 180.

25. Fernando III, a través de su embajador en Madrid, presenta sus excusas al respecto diciéndole que se arriesgaba a perder sus estados si no firmaba la paz y que podía llegar a perder la Corona imperial si no cedía ante las demandas de los electores en este punto. Sin embargo, le indicó que seguiría ayudando a su primo con otros medios y le seguiría proporcionando tropas bajo otras banderas para no violar los 
como una verdadera traición hacia sus intereses y los de su dinastía, aunque en privado confesó que entendía las razones que habían llevado a su primo a firmar tal paz. Como consecuencia de ello, las relaciones entre la Monarquía Hispánica y el Imperio atravesaron un momento problemático en los meses posteriores, pero ni se produjo una ruptura total de las relaciones entre ambas ramas de la familia ni se paralizó el matrimonio entre Felipe IV y la archiduquesa Mariana, que aún continuaba en Viena en el momento de la firma del tratado.

Lo que sí interrumpió la firma de la paz fue el viaje del archiduque Fernando a Madrid quien, con la excusa de acompañar a su hermana hasta su nueva casa, pretendía llegar hasta la corte para tratar personalmente el asunto de su matrimonio con la posible heredera de la Monarquía Hispánica. Felipe IV, que entendía este viaje como un movimiento de presión, no deseaba que se produjera, pero utilizó la posibilidad de negarle el paso a sus territorios a su sobrino como una forma más de intentar retrasar la firma de la paz por parte del emperador. Cuando esta se produjo, las órdenes del rey a su embajador extraordinario en Viena fueron tajantes: el archiduque no debía poner un solo pie en territorios de la Monarquía Hispánica ${ }^{26}$.

Esto no detuvo al emperador, que ansiaba la realización de este matrimonio, pese a que diversos sectores de la política imperial veían con desconfianza tanto la posibilidad de que ambas coronas recayeran en este hipotético matrimonio como que una nueva unión con sus parientes de Madrid pusiera en peligro la recién encontrada paz, recelando del hecho de que el emperador pudiera seguir ayudando a la Monarquía Hispánica con recursos que debían invertirse mejor en asuntos directamente vinculados a los intereses del Imperio ${ }^{27}$. El emperador deseaba no solo vincular la herencia hispana a su línea con este matrimonio, sino también reforzar las relaciones con Madrid que la firma unilateral de la paz de Westfalia por parte del Imperio habían dejado muy dañadas. Fernando III indicó a su primo que, si se negaba a recibir a su sobrino cuando el viaje estaba ya planeado y era ampliamente conocido, demostraría a sus enemigos que ambas ramas de la casa de Austria estaban separadas, algo de lo que intentarían aprovecharse y que no tenía razones para hacer tal cosa, dado que había prometido continuar ayudándole militarmente pese a la paz firmada ${ }^{28}$. Mientras intentaba convencer a su reacio primo, Fernando III mandó a su hijo a acompañar a su hermana durante su viaje a través de los territorios imperiales, esperando que Felipe IV reconsiderase su decisión y que, una vez llegara el archiduque a Madrid, se pudiera ejercer sobre él la suficiente presión como para fijar definitivamente el matrimonio ${ }^{29}$. Sin embar-

términos de la paz. Carta de Fernando III a Felipe IV, 21 de octubre del 1648. AHN, Estado, libro 712, s/f. Citado por Tercero Casado, Luis, «La jornada de la reina Mariana...», art. cit., p. 648.

26. Instrucción secreta de Felipe IV para el conde de Lumiares, 31 de enero de 1648. AHN, Estado, leg. 1635.

27. AHN, Estado, leg. 2353, Consulta del Consejo de Estado, 6 de diciembre de 1648. Citado por TERCERo CASAdo, Luis: «La jornada de la reina Mariana...», art. cit., p. 648.

28. Carta de Fernando III a Felipe IV, 21 de octubre del 1648. AHN, Estado, libro 712, s/f.

29. El marqués de Grana había incluso empezado a tramitar en Roma la emisión por parte del Papa de una dispensa de edad y parentesco para que el archiduque y la infanta pudieran casarse de manera inmediata. 
go, Felipe IV no cedió y el archiduque Fernando nunca llegó a pisar territorio de la Monarquía Hispánica, pues tuvo que darse la vuelta en Rovereto tras haber despedido a su hermana en la frontera de sus nuevos reinos.

En los años posteriores, cuando desde Viena se volvía a hablar del matrimonio, las respuestas de Felipe IV fueron siempre cordiales, sin indicar una negativa total pero sin proporcionar tampoco una respuesta positiva, en espera de ver lo que el tiempo dictaba como más conveniente. Durante los primeros años de su matrimonio con Mariana de Austria, el monarca utilizó con su primo imperial una doble estrategia. Por un lado, insinuaba de forma constante al emperador que no pensaba encontrar un marido para su hija fuera de su familia, pero que todavía no podía darle a su pariente una respuesta más concreta que la promesa de su amor y, por otro, utilizaba la amenaza velada, pero recurrente, de casar a su hija con Francia o con algún otro pretendiente si el emperador no prestaba a Felipe IV la ayuda que este pedía o su actuación no concordaba con sus intereses ${ }^{30}$.

Sin embargo, el heredero ansiado por Felipe IV no llegó en los años posteriores al nacimiento de la infanta Margarita, que tuvo lugar en el año 1651. El paso del tiempo sin el nacimiento de un heredero varón, la llegada de la infanta a una edad apta para el matrimonio y su salud cada vez más perjudicada hicieron que finalmente Felipe IV se decidiera en 1654 a casar a la infanta y asegurar el destino de la Monarquía Hispánica en el caso, cada vez más probable, de que el monarca pudiera morir sin tener un hijo varón.

En primer lugar, Felipe IV decidió jurar como heredera y sucesora legítima de sus territorios a la infanta María Teresa, algo que, según sus propias palabras, había

HHSTA, StAbt, Spanien-Varia, Karton 13, fasz. 12, carta de Grana a Trauttmansdorff fechada el 4 de diciembre de 1648. Citado por Tercero CASADO, Luis: «La jornada de la reina Mariana...», art. cit., pp. 652-653.

30. Ya antes de la firma de la paz de Westfalia, Felipe IV había intentado utilizar el matrimonio de la infanta con el archiduque como un arma con la que amenazar al emperador en contra de su firma, recomendándole que pensara que, si ratificaba la paz, podría verse obligado a casar a su hija con Francia: «[...] y si el emperador os replicare que yo no querré ningún tiempo dejar de asegurar mi subcesión a mis sobrinos caso que, lo que Dios no permita, me faltase subscesión de varón, vos le responderéis que su Magestad Cesárea debe considerar esto con atención, a que apartándose de mí podría yo llegar a verme en estado de ser menester tratar de casar a mi hija en Francia, y que nunca aconseja la Prudencia dejar de valerse de estremos remedios en los estremados peligros a que mi Hermano habrá dado potentíssima causa, por contemplación de los que le solicitan que concluya la Paz con mi exclusión, aunque sea con evidente peligro de la Pérdida de nuestra casa en ambas líneas [...]». Carta de Felipe IV al conde de Lumiares, 31 de enero de 1648. AHN, Estado, leg. 1635. Era una táctica que también empleaba el emperador, amenazando con casar a su hijo con otra candidata, ante las continuas respuestas vagas que le daba su primo. Por ejemplo, en una carta de Felipe IV a Fernando III fechada en junio de 1654, se decía lo siguiente: «[...] devo añadir que en caso que V. M. después de considerar bien sobre esta carta todavía resuelva executar el casamiento del Rey de Romanos mi sobrino, así como V. Magestad me ha representado los daños que se siguieran de casar a la Ynfante mi hija fuera de nuestra casa, quedo muy seguro de que V. Magestad no ha pensado ni pensará en casar al Rey mi sobrino en Françia, siendo tantos y tan notorios y tan reçíprocos los incombenientes que en la presente coyuntura de tiempos seguirían, si se viese que V. Magestad trata de emparentar con los enemigos desta Corona». RAH, Salazar y Castro, A-92, fol. 3. 
dejado de hacer durante mucho tiempo por no disgustar a la reina, demostrando de esta manera al mundo que ya no confiaba en que pudiera darle hijos varones ${ }^{31}$, algo que solo interrumpiría el anuncio de algún nuevo embarazo ${ }^{32}$. Asimismo, también anunció Felipe IV a su primo que se disponía a pedir al papa una dispensa matrimonial para poder casar a su hija con quien deseara en cualquier circunstancia, ya que, independientemente del novio que eligiera, este debía ser pariente de su hija en algún grado ${ }^{33}$.

Asimismo, la súbita muerte del rey Fernando IV el 9 de julio de 1654 hizo que Felipe IV tomase una resolución firme. Poco después de este hecho, Felipe IV decidió dar en matrimonio a su hija María Teresa al heredero del emperador y así se lo transmite a su embajador en Viena en su carta del 5 de abril de $1655^{34}$. Felipe IV indica continuamente en su correspondencia tanto con el emperador como con sus embajadores en Roma y en Viena la necesidad de asegurar el futuro de su hija en caso de que tuviera un hermano varón que la apartara de la sucesión, por lo que, ante la imposibilidad de dotarla adecuadamente si no se convertía en su sucesora, solo podría casarla con un heredero ${ }^{35}$. Además, solo el casamiento de la infanta con un heredero poderoso podría

31. Así se lo indica al emperador en su carta de 13 de junio de 1654 (AHN, Estado, libro 133, s/f.). Esta parte del contenido es prácticamente idéntico al que aparece en una carta fechada en el mismo mes que escribió Felipe IV a Fernando III y que se conserva en la RAH, colección Salazar y Castro, A-92, fols. 1v.-2v.

32. Esta será precisamente la razón de que nunca se llegara a realizar esta jura, pues el anuncio de tres nuevos embarazos de la reina en 1653, 1655 y 1657 la paralizaron, hasta que el nacimiento del príncipe Felipe Próspero acabó con este proyecto de forma definitiva.

33. «Por una parte, considero que no ha servido nuestro señor de darme hasta ahora hijo varón, que la reina tarda en hacerse preñada, que somos mortales y que tengo dos hijas y la maior en edad competente para poder casarse, aunque no tanta que no sufra algún año de dilación. Por otra parte considero ser continente y natural que Dios nos dé hijos varones y debiéndose de considerar sinceramente el casamiento de la infante mi hija en casso que se repute por heredera y en el casso de tener hermanos varones, e resuelto suspender por ahora la colocación de mi hija teniendo algún tiempo más para esperar lo que Dios será servido de disponer acerca de mi successión, [y] gobernarme conforme a ello en la elección de la persona con quién la é de casar, mas no pudiendo elegir alguno que no sea pariente que necesite de dispensación y desseando yo estar prevenido y resguardado para poder en qualquier accidente declarar sin impedimento mi voluntad y efectuar el casamiento de mi hija [...], por los escándalos y turbación que podrían resultar después della sobre el cassamiento». Carta de Felipe IV al papa Alejandro VII. Minuta de don Luis de Haro. RAH, Salazar y Castro, A-91, fols. 191r.-194r. También afirma lo mismo en la carta que envía a Fernando III mencionada en la nota anterior. AHN, Estado, libro 133, s/f.

34. Carta de Felipe IV del 5 de abril de 1655. AHN, Estado, libro 133, s/f.

35. Así se lo explica claramente a su embajador en Roma con las siguientes palabras: «Y qualquiera vee quan cierto es que yo no puedo determinar oy que marido he de dar a mi hija, pues [...] si oy se casasse la Infanta con quien no fuera príncipe heredero o heredado por dejarla suzessora destos Reynos y dentro de un año tuviese un hermano, y así e de considerar cómo quedaría y quan dificultoso sería dotharla de manera que asegurase el estado, comodidad y decoro que es razón». Carta de Felipe IV a su embajador en Roma. AHN, Ministerio de Asuntos Exteriores, Santa Sede, leg. 70, fols. 284v. Este documento, de fecha ilegible, se encuentra conservado junto a varios otros vinculados a la boda de Leopoldo I y la infanta Margarita, con los que se ha asociado. Sin embargo, su contenido no concuerda con las circunstancias de este matrimonio y sí guarda una gran similitud con otros testimonios que se pueden encontrar en la correspondencia intercambiada entre Felipe IV y su embajador en Viena y en sus cartas a Fernando III. Por lo tanto, podemos relacionar claramente este testimonio con el contexto de las negociaciones matri- 
ayudar a Felipe IV en los avatares de la guerra con Francia, ya fuera para darle fin si la casaba con Luis XIV o para obtener los medios necesarios para continuar con la guerra si la vinculaba a la herencia imperial, por lo que su matrimonio con un príncipe que no pudiera darle tales beneficios quedaba fuera de toda consideración ${ }^{36}$. Desde el punto de vista de Felipe IV, la herencia de la Monarquía debía permanecer dentro de su Casa, por lo que, teniendo en cuenta todas las consideraciones aquí apuntadas, el matrimonio con el heredero del emperador era la única opción viable mientras su hija fuera su heredera directa.

En su carta de 5 de abril de 1655, el rey asegura a su embajador en Viena sin ningún género de dudas que su deseo es casar a su hija con su sobrino, el archiduque Leopoldo Ignacio, aunque es consciente de los problemas que podía suponer unir el destino de la infanta al del primogénito del emperador ${ }^{37}$. Considerando imposible, no solo que el Imperio y la Monarquía pudieran ser gobernados por la misma persona, sino también que quien fuera a ser su yerno pudiera ser elegido emperador, Felipe IV presenta a su embajador la estrategia que considera más provechosa para la Monarquía Hispánica: que su sobrino Leopoldo Ignacio no intentase ser elegido como rey de Romanos, sino que, en su lugar, fuese nombrado sucesor imperial su tío, el archiduque Leopoldo Guillermo ${ }^{38}$.

moniales de la infanta María Teresa previas a la paz de los Pirineos. Hay que indicar, no obstante, que Rafael Valladares, que también menciona este documento, lo vincula a la infanta Margarita y no a María Teresa. Véase Valladares, Rafael: La rebelión de Portugal: guerra, conflicto..., op. cit., pp. 194-195.

36. Además de Luis XIV y de los hijos de Fernando III, el único candidato que fue tenido realmente en consideración por Felipe IV fue el joven duque de Saboya, Carlos Manuel. En un documento que se conserva en la Real Academia de la Historia, podemos ver cómo el cardenal Federico de Hesse trasmite a Luis de Haro una oferta de la regente y madre del duque, Cristina de Borbón en la que se dice que si se realiza el matrimonio entre el joven duque y la infanta española, Saboya devolvería a la Monarquía las ciudades ocupadas por éste en el estado de Milán y contaría con su apoyo en la guerra contra Francia. Sin embargo, esta candidatura, pese a que además de estas ventajas supondría la posibilidad de unir los territorios saboyanos a la Monarquía Hispánica, perdió pronto fuerza frente a las ofertas imperiales y francesas. RAH, colección Salazar y Castro, A-94, fols. 185-186.

37. «[...] Se considera el casamiento de los dos rodeado de reparos y dificultades que es preciso antever y prevenir, no solo porque yo no he de sugetar mi reynos a lo Riesgos en que se vieron en tiempos de mi visagüelo por las ausencias que hizo S. M. llevado de las obligaciones del Imperio, sino porque hallándome oy con dos guerras en España que obligan al gasto y cuidado que se dexan considerar, confesará qualquiera quanto se aumentan los Riesgos que se han apuntado, se disminuien los medios y las fuerzas para acudir a los de fuera y se imposibilita de todo punto el apartarse y hacer ausencia de estos Reynos el que los ha de governar. y si estas consideraciones se junta la repugnancia que harán franceses, suzeses y alemanes, émulos y enemigos de nuestra casa, quando vean que se trata y se pretende hacer Rey de Romanos al que yo elijo para hierno, hallándome si hijo varón, pareze que de todo puto se hará imposible efectuar la elección y el pretenderla sería con evidente riesgo de turbar la paz de Alemania». Carta del rey Felipe IV a su embajador en Viena, fechada el 5 de abril de 1655. AHN, Estado, libro 133, s/f.

38. «[...] mas para salvar los inconvenientes que quedan apuntados, supuesto que yo no tengo hijo, el medio que se representa es que tratemos con toda la aplicación de que sea elegido Rey de Romanos el Archiduque Leopoldo Guillermo mi Primo, de manera que quando yo no tenga hijo Barón, sea sucessor en el Imperio el Archiduque Leopoldo Guillermo y en estos Reynos lo sea el Archiduque Leopoldo 
De esta forma, el archiduque Leopoldo Ignacio quedaría libre para ir a la península Ibérica para casarse con la infanta y permanecer la pareja allí en caso de que no tuviera un hijo varón, manteniéndose separadas ambas herencias de la casa Habsburgo y conjurándose así una de las preocupaciones más importantes que tenía el monarca respecto al casamiento de su hija: conseguir que esta permaneciera dentro de sus fronteras mientras fuese su heredera. Asimismo, esta opción también le parecía conveniente para asegurar el futuro de su hija, pues si él tuviera un hijo varón, la pareja podría volver al Imperio y ser nombrado Leopoldo rey de Romanos, dado que el archiduque Leopoldo Guillermo no tenía hijos ni parecía que fuera a tenerlos en el futuro. En caso contrario, si no los tuviera, Leopoldo Guillermo podría nombrar como heredero al segundo hijo varón de Fernando III, el archiduque Carlos José, por lo que en cualquier caso quedarían ambas coronas en manos de la Casa de Austria ${ }^{39}$. Incluso, según propone a su primo, podría ser posible que la pareja tuviera hijos en vida tanto de Felipe IV como de Fernando III, pudiendo volverse al Imperio en pocos años dejando asegurada la herencia hispana en sus descendientes.

Para la Monarquía Hispánica, era la solución ideal, por lo que su embajador debía «aplicar[se] para persuadir al Emperador (si haya en él alguna repugnancia) que este remedio sólo puede salvar los inconvenientes mayores, facilitando la declaración que desea de mí por conviniendo su dictamen con el mío, luego se podrá efectuar el casamiento de mi hija $»^{40} \mathrm{y}$ también salvar cualquier oposición a este matrimonio que pudiera proceder del entorno del emperador ${ }^{41}$, «porque para resolverme yo de presente a casar con efecto mi hija, es menester que sea con el Archiduque Leopoldo Ygnacio ${ }^{42}$.

Sin embargo, Fernando III no aceptó con los brazos abiertos esta posibilidad. Para el emperador, esta idea significaba apartar a su heredero directo de la sucesión de los territorios que le pertenecían y anteponer las conveniencias de la Monarquía Hispánica a las del Imperio y a las de sus territorios patrimoniales. Tan poco dispuesto a dejar salir a su heredero de sus reinos como el propio Felipe IV, Fernando III expuso a su primo las razones por las que no creía conveniente poner en práctica la mencionada estrategia. Entre otras consideraciones, no pensaba que era adecuado nombrar como heredero a su hermano, «porque el Emperador, siendo casi de una misma hedad con él, no necesita de coadjuntar, se alterarían las disposiciones paternas y la primogenitura también $\mathrm{y}$, aunque pareze esto pudiera remediarse con darle solamente el usufruto de

Ygnacio». Carta del rey Felipe IV a su embajador en Viena, fechada el 5 de abril de 1655. AHN, Estado, libro 133, s/f.

39. Carta del rey Felipe IV a su embajador en Viena, fechada el 5 de abril de 1655. AHN, Estado, libro 133, $\mathrm{s} / \mathrm{f}$.

40. Carta del rey Felipe IV a su embajador en Viena, fechada el 5 de abril de 1655. AHN, Estado, libro 133, $\mathrm{s} / \mathrm{f}$.

41. Carta del rey Felipe IV a su embajador en Viena, fechada el 5 de abril de 1655. AHN, Estado, libro 133, $\mathrm{s} / \mathrm{f}$.

42. Carta del rey Felipe IV a su embajador en Viena, fechada el 5 de abril de 1655. AHN, Estado, libro 133, $\mathrm{s} / \mathrm{f}$. 
algunos bienes, hacerle dar reversales estrechísimos, ponerle ministros al lado de entera confianza y, con ser él de suyo dependiente del hermano (pues se quieren muy entrañablemente) con todo eso es muy fresca la memoria de lo que pasó entre el Emperador Rudolfo y su hermano Mathías, y con mucho menores ocasiones que no fueran las que el ahora tuviera» ${ }^{43}$. Además, también quedaría la preocupación de lo que podría pasar si el archiduque Leopoldo Guillermo muriera al mismo tiempo que Fernando III, dado que sus edades y achaques eran similares, pues el archiduque Carlos José era todavía demasiado joven, tanto para ser elegido emperador como para gobernar los estados patrimoniales de los Habsburgo, por lo que se podría perder el Imperio para su Casa y poner en riesgo sus estados con una peligrosa regencia. Por último, pero no por ello menos importante, los electores, al ver que se preocupaban más por las cosas de la Monarquía Hispánica que por los asuntos del Imperio, «pudieran pensar en la total preterición de la Casa de Austria ${ }^{44}$. Por todo ello, lo mejor para la casa de Austria, según el emperador Fernando III, era que Felipe IV casara a María Teresa no con el entonces archiduque Leopoldo Ignacio, sino con otro miembro de la dinastía Habsburgo, el archiduque Segismundo Francisco del Tirol, entonces heredero de su hermano el archiduque Fernando Carlos ${ }^{45}$. Así, la herencia de la Monarquía Hispánica permanecería dentro de la dinastía, María Teresa y su marido podrían permanecer sin problemas en Madrid y su hijo Leopoldo podría heredar su lugar en el Imperio y en sus territorios patrimoniales.

Esto no entraba en los planes de Felipe IV, que se negaba a casar a su hija con una rama secundaria de la Casa que no podría ni ayudarle en la guerra ni proporcionar a la infanta un destino decoroso si no se convertía en su heredera. Pero las presiones de Felipe IV no sirvieron para mover al emperador de su posición ${ }^{46}$. Según declaraba el marqués de Castel Rodrigo, lo que el emperador deseaba era dejar que pasara el tiempo sin dar una negativa rotunda a su primo pero sin aceptar un acuerdo que no deseaba, mientras continuaba negociando con los electores el nombramiento de Leopoldo Ignacio como Rey de Romanos. Así, con su primogénito elegido como sucesor del Imperio, se vería Felipe IV obligado a aceptar al archiduque Segismundo como yerno, al haber declarado él mismo que ambas herencias eran incompatibles ${ }^{47}$.

El anuncio del nuevo embarazo de la reina en 1655 interrumpe las conversaciones en este punto, a la espera de que nazca un varón que cambie completamente la situa-

43. Carta del emperador Fernando III a Felipe IV de 24 de julio de 1655. AHN, Estado, libro 133, s/f.

44. Carta del emperador Fernando III a Felipe IV de 24 de julio de 1655. AHN, Estado, libro 133, s/f.

45. Carta del emperador Fernando III a Felipe IV de 24 de julio de 1655. AHN, Estado, libro 133, s/f.

46. A este respecto, véase el capítulo «Leopold Ignaz - ein neuer Karl V.?» de la obra de Löthar Höbelt «Ferdinand III (1608-1657). Friedenskaiser wider Willen», Granz, 2008, pp. 382-387, donde se indica repetidamente que el emperador no permitiría que su heredero saliese de sus territorios, como, por ejemplo, se ve en las instrucciones que escribe Fernando III a su embajador en Madrid, el conde de Lamberg, fechadas el 18 de noviembre de 1654 .

47. Carta del marqués de Castel Rodrigo, embajador en la corte imperial, a Felipe IV, fechada el 16 de julio de 1655. AHN, Estado, libro 133, s/f. 
ción ${ }^{48}$. Sin embargo, el nacimiento y muerte de la infanta María Ambrosia en diciembre de ese mismo año dejó todo como estaba y Felipe IV retomó con renovado vigor las negociaciones matrimoniales a través de su nuevo embajador en Viena, el marqués de La Fuente. A este último, sin dejar de alabar la opción matrimonial francesa, que tilda de la más oportuna si él tuviera hijos varones ${ }^{49}$, le indica la necesidad de que el matrimonio de la infanta con el ya rey de Hungría se hiciera realidad lo antes posible de la manera más provechosa para la Monarquía Hispánica. La primera misión del marqués de La Fuente era, en palabras del propio Felipe IV, «procurar que la respuesta deste despacho sea decirme el Emperador mi hermano queda dispuesto a enviarme luego a mi sobrino, porque con menor demostración no pagaría la fineza de mi voluntad $»^{50}$.

El archiduque debía viajar lo antes posible a Madrid ${ }^{51}$ y que, en cuanto el emperador diese una respuesta afirmativa, se enviarían las órdenes correspondientes a los virreyes para que tuvieran dispuesto tanto las naves como cualquier otra consideración necesaria para su viaje a la Península ${ }^{52}$. Felipe IV no aceptaría ninguna otra disposición y el embajador debía vencer las reticencias que ya había mostrado el emperador a este respecto en el pasado recordándole que el rey podía verse obligado a casar a su posible heredera en Francia si no se le enviaba a su sobrino ${ }^{53}$. Sin embargo, el embajador

48. Cartas de Felipe IV al Emperador y a su embajador en Viena del 16 de septiembre de 1655. AHN, Estado, libro $133, \mathrm{~s} / \mathrm{f}$

49. «Con que se dice que estando la Monarchia acometida de tantos y tan fuertes enemigos y tan exenta de medios después de los crecidos gastos y que obliga la porfía a la duración de la Guerra, las leyes de la prudencia aconsejan que se tome partido que salve tan peligrosos inconvenientes aunque sea aventurando algo y mucho en lo futuro, por salir del peligro presente [...] que dándonos Dios hijos Barones no hay duda que este matrimonio [el de María Teresa y Luis XIV] sería combinientísmo». Carta de Felipe IV al marqués de La Fuente del 22 de marzo de 1656. AHN, Estado, libro 133, s/f.

50. Carta de Felipe IV al marqués de La Fuente del 22 de marzo de 1656. AHN, Estado, libro 133, s/f

51. «La elección de Rey de Romanos y la utilidad de asegurarla en el Rey mi sobrino primogénito del Emperador no pareze que sean reparos que puedan dilatar este casamiento, antes de estimular el ánimo del Emperador para abreviarle, porque son muchos muy contingentes los acaecimientos los quales o qualquiera ellos podrá mi sobrino volver a Alemania sin haver hecho falta en este otro intento, porque si nuestro señor fuese servido de darme hijo Barón o, si no dignándose de dármelo me diese un nieto, mi sobrino se hallaría en disposición de volver a Alemania y en el tiempo de dos años y aun en menos, se puede esperar naturalmente uno u otro y aun todo; véase pues si por esta breve ausencia sería bien escusar la efectuación del casamiento y si la calidad del negocio vale lo que se dilate la pretensión de Rey de Romanos o que se haga la negociación necesaria en ausencia del Rey». Carta de Felipe IV al marqués de La Fuente del 22 de marzo de 1656. AHN, Estado, libro 133, s/f.

52. «La forma más expediente para su pasaje se dexa a la prudente disposición del Emperador, lo que acá se discurre en este punto es que la prontitud y diligencia no esperada suele ser en semejantes casos más segura que la fuerza prevenida y publicada con preparamientos muy ruidosos y así se juzga que el Rey, mi sobrino, debería transferirse de incógnito y con solo 6 ó 8 criados, a la parte donde pareciere que se embarque y con ella estén prevenidas las galeras que fueren menester de las esquadras de Italia y que llegado a estos Reynos halle puesta la Casa y prevenido todo lo necesario para su servicio y regalo, con la decencia y autoridad que por tantas razones le es devido, siendo quien es y viniendo a lo que viene». Carta de Felipe IV al marqués de La Fuente del 22 de marzo de 1656. AHN, Estado, libro 133, s/f.

53. Carta de Felipe IV al marqués de La Fuente del 22 de marzo de 1656. AHN, Estado, libro 133, s/f. 
no consiguió su objetivo y la muerte sorprendió a Fernando III el 2 de abril de 1657 sin aceptar que su heredero saliese de sus territorios para casarse con la infanta María Teresa.

\section{7: EL AÑO CLAVE}

En el mismo mes en el que se producía la muerte de Fernando III, su hijo y heredero ya demostró que tenía unas ideas distintas a las de su padre en lo que se refería a su posible matrimonio con la heredera de la Monarquía Hispánica, pues rápidamente hizo saber a su tío su buena disposición para partir hacia la península Ibérica lo ante posible, pese a que esto entraba directamente en conflicto con sus posibilidades de suceder en el solio imperial ${ }^{54}$. Así indica el marqués de La Fuente haberle dicho el rey de Hungría «[...] que de su parte solo podía poner el desseo de llegar quanto antes a los pies de V. M. dejando la disposición en el modo, en el tiempo y en todo lo demás a lo que V. M. ordenase ${ }^{55}$.

Esta declaración de Leopoldo Ignacio se podía equiparar a una verdadera renuncia del solio imperial, pues se conocía que los príncipes electores no elegirían como emperador al posible heredero de la Monarquía Hispánica. Así se lo indican en una reunión el príncipe de Auersperg y los condes de Porcia, de Schwarzenberg y de Pötting al marqués de la Fuente, al que hablan de acelerar el pasaje de Leopoldo Ignacio a Madrid, con el objetivo de que no se encontrara en Alemania en el momento de la elección ${ }^{56}$.

54. En un papel que el príncipe de Auersperg entrega al marqués de La Fuente, se presentaban las razones que esgrimía el joven rey de Hungría para preferir el pasaje a la Monarquía Hispánica a la posibilidad de suceder en el Imperio: «Los verdaderos motivos porque S. M. el rey de Ungría prefiere la hida a España y el casamiento con la infanta a qualquier otra esperanza son que más importa a entrambas líneas el conservarlas unidas con este casamiento, aunque el señor Emperador caiga sobre cualquiera de los archiduques por esta vez; que no que el Rey de Ungría se elija emperador y la Monarchia de España se desune con el casamiento de Francia o Saboya o qualquiera otro fuera de esta casa, luego el querer unir el Imperio con la Monarchia de España en una cabeza, ni fue practicable en tiempo de Carlos $5 .^{\circ}$ y ni parece que oy lo pueda ser, antes el solo tentarlo podrá poner en riesgo lo uno y lo otro y las coronas y los mal afectos tomarían ocasión a persuadir a los electores para que con tal pretexto echen mano a qualquiera otro fuera de esta Augustíssima Casa y por esto desea el Rey embarcarse quanto antes y al fin de agosto a lo más tarde para que en tiempo de la elección no se halle en Alemania a fin que con su presencia no se obligue a los electores pensar en él y ponerle por condición infalible de su elección que él para siempre renuncie al casamiento de la Infanta y gobierno de España y no dé más socorro a ella, con que estorvaría la elección de qualquiera de su Casa, y quando cayese en su cabeza, se desuniría la Monarchia de España en total ruina de entrambos y triunfo de sus enemigos». Copia del papel que el príncipe de Auersperg dio al marqués de la Fuente. Incluido en la carta del marqués de la Fuente, embajador en Viena, a Felipe IV de 20 de abril de 1657. AHN, Estado, libro 125, pp. 101v.-102v.

55. Carta del marqués de la Fuente, embajador en Viena, a Felipe IV de 20 de abril de 1657. AHN, Estado, libro 125 , p. $95 \mathrm{r}$.

56. «[...] Por no perder tiempo sería bien que escribiese a los ministros de Italia que hubiesen de cooperar en las disposiciones del viaje para que las fuesen adelantando [...], no era menos conviniente que no le cogiese octubre en la mar; que si bien para la poca casa con que hirá vastarían pocas galeras, para todo lo demás convendría que el número fuese el que V. M. juzgase suficiente para el decoro y para asegurar 
Tras esta reunión, el marqués de la Fuente indicó claramente a Felipe IV que «[...] me ha parecido anticipar a V. M. la noticia de lo que por vía de discurso ha pasado y así en quanto a lo primero iré que reconociendo por lo que me participaron en orden al viaje de S. M. que no pensaba en proponer su Persona $\rangle^{57}$.

Esto se encontraba en consonancia con los deseos expresados por Felipe IV en los años anteriores, por lo que, aunque el embajador advierte a sus interlocutores imperiales que era una temeridad que apartasen totalmente a Leopoldo Ignacio de la sucesión imperial, se dispuso a apoyar la candidatura del archiduque Leopoldo Guillermo y trabajar para que, en cualquier caso, el solio imperial se mantuviera en la Casa Habsburgo ${ }^{58}$. Tan seguro estaba en un primer momento que esta estrategia se adecuaba totalmente con los deseos de Felipe IV que el marqués de La Fuente que llegó a discurrir con el conde de Porcia sobre el mejor gobierno que se podía dejar en los territorios patrimoniales del rey de Hungría durante su ausencia, de modo que pudiera seguir controlándolas desde la distancia como el rey Católico hacía con sus territorios más lejanos ${ }^{59}$.

Sin embargo, en este momento en el que parece que todo se amoldaba por fin a los deseos de Felipe IV en relación al matrimonio de su hija, después de años de negociaciones fallidas con Fernando III, fue el monarca hispano el que cambió de opinión y, lejos de promover el viaje de su sobrino, indicó a su embajador que debe intentar por todos los medios conseguir que el elegido como emperador fuera Leopoldo Ignacio y no su tío el archiduque Leopoldo Guillermo ${ }^{60}$. En la correspondencia que intercambia con el marqués de La Fuente no se indica claramente a qué obedece este cambio de estrategia. La confirmación del embarazo de la reina Mariana, del que nacería final-

la persona del rey sino de una Armada que se formase para hacer oposición al pasaje, por lo menos para que no fueses expuesto al desaire y al riesgo que podrían ocasionar los Navíos de naciones enemigas que en número tan considerable andaban en corso, [...] y en quanto a los ministros dije que solo al Virrey de Nápoles parezía necesario decirle algo porque en caso de llegar alguna esquadra no la empeñase en cosa que al tiempo destinado no pudiese estar pronta para executar las órdenes de V. M., pues para detener las Galeras era bastante pretexto el de la guerra de Lombardía.». Carta del marqués de la Fuente, embajador en Viena, a Felipe IV de 20 de abril de 1657. AHN, Estado, libro 125, pp. 96r-97v.

57. Carta del marqués de la Fuente, embajador en Viena, a Felipe IV de 20 de abril de 1657. AHN, Estado, libro 125, p. $97 \mathrm{v}$.

58. Carta del marqués de la Fuente, embajador en Viena, a Felipe IV de 20 de abril de 1657. AHN, Estado, libro 125 , pp. $97 \mathrm{v} .-98 \mathrm{r}$.

59. «En el segundo punto ha discurrido con el conde de Porcia encargándole la atención de que (en caso de salir de aquí S. M. quando se supone) procure que se ajuste el gobierno de tal forma que bien que esté en España el Rey pueda disponer en sus provincias como dispone V. M. de quantas tiene a una distancia más remota y aunque las gobernase un hermano y me pareció preciso prevenir esto quando ay muchos cassos en que si bien se efectúe el casamiento pueda volver aquí S. M. y hallarse sin más que lo que oy posee, con lo que es preciso procurar conservarlo unido sin abrir puerta para que pueda alterarse en nada la primogenitura». Carta del marqués de la Fuente, embajador en Viena, a Felipe IV de 20 de abril de 1657. AHN, Estado, libro 125, pp. 99r-100v.

60. Carta del marqués de La Fuente a Felipe IV fechada el 15 de junio de 1657. AHN, Estado, libro 125, pp. $168 \mathrm{v} .-168 \mathrm{r}$. 
mente el ansiado varón, el príncipe Felipe Próspero, no se puede considerar como razón suficiente para este cambio, dado que no se sabía cuál sería su fruto cuando el rey decide apoyar la candidatura del rey de Hungría al Imperio y los anteriores embarazos de la reina habían supuesto una congelación de las negociaciones matrimoniales, pero no habían propiciado un cambio de parecer tan radical al respecto por parte del rey.

Parece más probable pensar que la relación problemática que Felipe IV mantenía con el archiduque Leopoldo Guillermo después de sus últimos años de gobierno en los Países Bajos ${ }^{61}$, le hubiera hecho reconsiderar la situación. De poco serviría a los intereses de Felipe IV casar a su hija con Leopoldo Ignacio si el titular del Imperio no le prestaba la ayuda que necesitaba para continuar la guerra y las noticias que le transmitía el Marqués de La Fuente respecto a la actitud para con la Monarquía Hispánica del archiduque Leopoldo Guillermo distaban mucho de ser halagüeñas ${ }^{62}$. Las relaciones cada vez más complicadas entre Felipe IV y Leopoldo Guillermo y los riesgos que su ascenso al solio imperial podían suponer para los intereses de la Monarquía Hispánica pudieron empujar a Felipe IV a cambiar una táctica que había mantenido intacta durante años, a la espera de que todavía pudiera nacerle un hijo que alejara a María Teresa del trono.

Sin duda, tanto aquellos príncipes electores como miembros influyentes de la corte de Viena que se oponían a que el Imperio siguiera prestando ayuda y apoyando a la Monarquía Hispánica consideraban que la candidatura del archiduque Leopoldo Guillermo era más segura para sus intereses. Así, el marqués de La Fuente indica que el elector de Colonia había dicho lo siguiente: «que la corona no podía salir de la casa de Austria, bien que en la persona del Rey [Leopoldo Ignacio] no había que pensar por sus pocos años, por el gobierno que tendría, porque se trataba el casamiento con la señora Infante, porque no se podía evitar el daño que recivía el Imperio y el riesgo que se exponían los socorros que se aplicavan a la defensa de las Provincias de V. M., pues si el Rey entrava al Gobierno continuaría como hasta aquí, y que

61. Sobre Leopoldo Guillermo, véase los trabajos de SchreIBER, Renate, «Entre dos frentes: el archiduque Leopoldo Guillermo como gobernador de Bruselas», en MARTínez Millán, José, y González Cuerva, Rubén (coords.): La dinastía de los Austria.., op. cit., Madrid, 2011, vol. 1, pp. 609-630 y, dentro de la misma publicación y volumen, la investigación de René Vermeir, «Un austriaco en Flandes. El archiduque Leopoldo Guillermo, gobernador general de los Países Bajos meridionales (1647-1656)», pp. 583-608.

62. Por ejemplo, cuando el marqués de La Fuente transmite a Felipe IV algunos inconvenientes que se presentaban a la elección del rey de Hungría como emperador, decía que una de las pegas que ponía el elector de Colonia era que si se elegía a Leopoldo Ignacio, se seguiría prestando ayuda y socorros a la Monarquía Hispánica. Aunque el embajador respondió al elector rápidamente que «cometían error tan grande como el de persuadirse a que si él [el archiduque Leopoldo Guillermo] fuese elegido no socorrería a los estados de V. Magestad con la misma fineza que el Rey». (Carta del marqués de La Fuente a Felipe IV del 15 de junio de 1657, AHN, Estado, libro 125, pp. 169r.-170v). Los rumores o posibles muestras de distanciamiento entre el archiduque Leopoldo Guillermo y los intereses de la Monarquía continúan viéndose en la correspondencia diplomática de estos años, pues en 1659, dice claramente el marqués de La Fuente que «en el señor Archiduque tiene el servicio de V. M. una durísima oposición». Carta del marqués de la Fuente a Felipe IV de 23 de abril de 1659. AHN, Estado, libro 126, p. 136v. 
todo se remediaría anteponiendo la persona de S. A.» ${ }^{63}$. Según el marqués de La Fuente, el archiduque Leopoldo trataba de alzarse como el mejor candidato de la casa Habsburgo para ser elegido como emperador y el rey de Hungría no parecía realizar movimiento alguno para impedírselo, fiel a su deseo de pasar a Madrid para casarse con la infanta ${ }^{64}$.

El monarca continuaba apoyando la candidatura de su sobrino Leopoldo Ignacio a la sucesión imperial cuando el 28 de noviembre de 1657 cambió por completo la situación política de la Monarquía Hispánica una vez más, pues ese día nació el príncipe Felipe Próspero de Austria. Felipe IV ya tenía a su ansiado heredero varón y la infanta María Teresa, tras once años como heredera, se vio relegada de su posición como sucesora. Esto tuvo varias consecuencias directas, de las cuales podemos considerar aquí dos como las más destacadas para el tema que nos ocupa. La primera, que Leopoldo ya no tenía que elegir entre el solio imperial y la herencia de la Monarquía Hispánica, ya que su posible esposa ya no era la heredera de su padre. María Teresa ya podría viajar a Viena, por lo que no se vuelve a hablar del posible paso de Leopoldo Ignacio a Madrid ni de su renuncia a ser elegido emperador. Pero, en segundo lugar, también significaba que Felipe IV tenía de repente una mayor libertad para negociar el destino matrimonial de su hija. Y esto precisamente ponía de nuevo en el mapa la posibilidad de una alianza matrimonial que Felipe IV no se había permitido considerar realmente mientras María Teresa fue su heredera: el matrimonio con Francia.

Como hemos mencionado anteriormente, el mismo Felipe IV había indicado al marqués de La Fuente años antes que el matrimonio de su hija con el rey francés sería el más conveniente para la Monarquía Hispánica si él dispusiera de un heredero varón. De hecho, en 1656, en las mismas instrucciones en las que indicaba a su embajador en Viena que debía intentar conseguir que Fernando III enviase a su hijo a Madrid para casarse con la infanta lo antes posible, el monarca decía lo siguiente: "Que en medio de tantas dificultades, nos ha dexado Dios con singular providencia el subterfugio de este remedio y que por ventura dilata el darnos hijos Barones para que, siendo mayor la esperanza de franceses [de conseguir la mano de María Teresa], les obligue a ser más liverales y más prontos a venir en qualquier partido de paz» ${ }^{65}$. En este momento, por primera vez desde 1646, Felipe IV se encontraba en una posición en la que podía considerar esa posibilidad, especialmente después de confirmarse otro embarazo de la

63. Carta del marqués de La Fuente a Felipe IV del 15 de junio de 1657, AHN, Estado, libro 125, pp. 169v.169 r.

64. «[...] fui a Laxsemburg donde hallándolos juntos [al rey Leopoldo y a su tío Leopoldo Guillermo] emplee la mayor parte de ora y media tratando de la elección y reconociendo en cada palabra de S. A. la destemplaza con que desseava anteponer su persona [...] en todo este tiempo no habló otra palabra el Rey (Dios le guarde) que la de decir que no vendría en aventurar el ser hijo de V. M. aunque perdiese dos Imperios, a que satisfize diziéndole que esperaba en Nuestro Señor y en S. A. que encaminaría el que consiguiese uno y otro». Carta del marqués de La Fuente a Felipe IV de 30 de mayo de 1657. AHN, Estado, libro 125, pp. 152v.-152r.

65. Carta de Felipe IV al marqués de La Fuente de 22 de marzo de 1656. AHN, Estado, libro 133, s/f. 
reina, que daría a luz al infante Fernando Tomás al año siguiente. El matrimonio que el rey de Hungría consideraba seguro se convertía, de repente, en algo incierto, por lo que redobló sus presiones para que su tío hiciese realidad el matrimonio prometido durante el año 1658, especialmente después de su elección como emperador el 18 de julio de ese mismo año. Durante dicho año, las conversaciones matrimoniales se congelan; ni se confirman mediante la firma de capitulaciones o su publicación, ni el rey se desdice de las promesas ya hechas. En el Imperio sabían perfectamente que no habría ninguna seguridad de la realización de este matrimonio hasta que la infanta no fuera enviada a Viena o, al menos, fuera publicado el enlace, por lo que se redoblan los intentos de Leopoldo I por obtener la novia prometida y por la que estuvo dispuesto a renunciar a la posibilidad de ser emperador sin tener la seguridad total de que llegara a ser rey de la Monarquía Hispánica.

A partir de la elección de Leopoldo I como emperador, la cuestión de la mano de la infanta parece vincularse prácticamente en exclusiva al problema de los socorros. Felipe IV dejaba traslucir que no daría una respuesta clara (ni la mano de la infanta) a su sobrino a no ser que le proveyera de mayores medios para defender sus territo$\operatorname{rios}^{66}$. Si no se le proporcionaba la ayuda que requería, el rey afirmaba que intentará mantener la integridad de sus estados de otra manera. Por su parte, Leopoldo I y sus consejeros indican al rey que no tomarían resolución sobre los subsidios a no ser se anunciara públicamente que daría a Leopoldo la mano de la infanta en matrimonio. Las conversaciones entre ambas partes se convierten en un constante tira y afloja en el que ninguna de las partes está dispuesta a ceder. Pero, en cualquier caso, el monarca considera que la promesa firme de matrimonio, realizada dos años antes, no es aplicable a las circunstancias que vivía en ese momento y que era libre de elegir otro destino para su hija, aunque decide seguir intentando conseguir la mayor cantidad posible de ayuda por parte del Imperio, en previsión de que las conversaciones que proyectaba con Francia no tuvieran el resultado esperado. El 21 de diciembre de 1658, Felipe IV celebró la llegada de un nuevo varón y ya con dos posibles herederos, decide enviar a la corte de Francia a don Antonio Pimentel para proceder a las conversaciones de paz con

66. «Ayer tarde vino a mí el conde de Porcia enviado de parte del Emperador. Propúsome la necesidad y combeniencia de casar a S. M. C. sin dilación y juntamente el deseo que S. M. tiene de casar con la señora Infante [...] y añadí que V. M. había dado bastante satisfacción del amor que tenía a su sobrino si puesto que le antepuso a todos quando trató de casar a la señora Infante sin tener hijo Barón, y que así no se podía ni debía olvidar del buen afecto de V. M. en este manejo y que a todo mi entender solo el emperador y sus ministros podían obligar a V. M. a mudarse y tomar otro hierro, que yo había experimentado que dexavan perder los Estados de Flandes con poca o ninguna consideración, en todo esto de unión de intereses entre las dos líneas eran palabras, pero que la verdadera separación era de obras, que V. M. había menester hazer la Paz como quisiesen los enemigos mientras no tuviese forma para hazer la guerra con alguna probabilidad y esperanza de defenderse; respóndiome que el emperador quería y deseaba socorrer da V. M. pero que tenía sobre sí las fuerzas del Turco y de Suezia, respondile que este era un cantar viejo». Carta del marqués de La Fuente a Felipe IV de 19 de noviembre de 1658. AHN, Estado, libro 134, pp. 15v.-15r. 
el reino vecino ${ }^{67}$ utilizando el único medio que tiene para conseguir una paz honrosa: la mano de la infanta María Teresa, dejando a su sobrino Leopoldo en espera hasta la firma de este tratado de paz y, finalmente, sin novia después de más de doce años de negociaciones entre ambas cortes.

\section{CONCLUSIONES}

Como se ha indicado en las líneas anteriores, el problema de la sucesión de la Monarquía Hispánica influyó enormemente en la política europea de la segunda mitad del siglo XVII. Desde la muerte del príncipe Baltasar Carlos en 1646 hasta el estallido de la guerra de Sucesión Española después de la muerte de Carlos II en el año 1700, la inestabilidad sucesoria condicionó la política de la Monarquía Hispánica y, también, la del resto de Europa, que trataba de obtener el máximo beneficio de la coyuntura hispana. Tan importante fue esta circunstancia en el devenir de la política europea en el medio siglo anterior al estallido propiamente dicho de la guerra de Sucesión Española que, lejos de poder considerarse un simple prolegómeno al conflicto bélico en sí, podemos ver el desarrollo de una auténtica guerra diplomática de sucesión entre los años 1646 y 1700.

La negociación del enlace de la infanta María Teresa con el que llegaría a ser emperador Leopoldo I muestra claramente la influencia que el problema sucesorio tuvo en el devenir político europeo ya en la década de los 50 del siglo XVII. Como se ha podido demostrar en las líneas anteriores, lejos de la concepción generalizada de que Felipe IV no llegó a tomar una decisión firme sobre el enlace de su hija antes del nacimiento del príncipe Felipe Próspero, la documentación diplomática refleja que el rey ya había tomado una decisión a favor del enlace entre María Teresa y Leopoldo en una fecha tan temprana como eran los primeros meses del año 1655 y que fueron solo las reticencias del emperador a dejar salir de sus territorios a su heredero (la misma preocupación que su primo compartía), poniendo en peligro la sucesión en su línea a la Corona imperial, lo que evitó su celebración en vida de Fernando III, tradicionalmente presentado por la historiografía española como el más interesado en que esta negociación llegara a buen puerto.

Finalmente, la correspondencia intercambiada entre Felipe IV y su embajador en Viena, el marqués de la Fuente, en el año 1657, demuestra que el nuevo y joven emperador Leopoldo I sí aceptó los términos de Felipe IV y que estuvo a punto de sacrificar su sucesión al Imperio para convertirse en el prospectivo heredero de la Monarquía Hispánica. La desconfianza creciente de Felipe IV hacia el archiduque Leopoldo Guillermo y, sobre todo, el azar del nacimiento de un príncipe varón para la Monarquía Hispánica cuando ya muchos no esperaban que se produjera detuvo en seco y, con el tiempo, puso fin a un proyecto matrimonial que, de haberse llevado a cabo, hubiera cambiado totalmente el devenir de la historia de Europa.

67. Saltillo, Marqués del: «Don Antonio de Pimentel de Prado y la paz de los Pirineos», Hispania: revista española de Historia, 26 (1947), pp. 24-124. 